\title{
Association between BRAF mutant classification and the efficacy of pemetrexed-based chemotherapy in Chinese advanced non- small cell lung cancer patients: a multicenter retrospective study
}

\author{
Lei Lei ${ }^{1 \#}$, Wen-Xian Wang ${ }^{1 \#}$, You-Cai Zhu ${ }^{2}$, Xing-Xiang Pu ${ }^{3}$, Yong Fang ${ }^{4}$, Hong Wang ${ }^{5}$, Wu Zhuang ${ }^{6}$, \\ Yin-Bin Zhang ${ }^{7}$, Li-Ping Wang ${ }^{8}$, Chun-Wei Xu', Mei-Yu Fang ${ }^{1}$ \\ ${ }^{1}$ Department of Chemotherapy, Chinese Academy of Sciences University Cancer Hospital (Zhejiang Cancer Hospital), Hangzhou, China; \\ ${ }^{2}$ Department of Thoracic Disease Center, Zhejiang Rongjun Hospital, Jiaxing, China; ${ }^{3}$ Department of Medical Oncology, Hunan Cancer Hospital, \\ the Affiliated Cancer Hospital of Xiangya School of Medicine, Central South University, Changsha, China; ${ }^{4}$ Department of Oncology, Sir Run \\ Run Shaw Hospital, Hangzhou, China; ${ }^{5}$ Department of Lung Cancer, the Fifth Medical Center, General of PLA, Beijing, China; ${ }^{6}$ Department of \\ Medical Oncology, Fujian Cancer Hospital, Fujian Medical University Cancer Hospital, Fuzhou, China; ${ }^{7}$ Department of Oncology, the Second \\ Affiliated Hospital of Medical College, Xi'an Jiaotong University, Xi'an, China; ${ }^{8}$ Department of Oncology, Baotou Cancer Hospital, Baotou, China; \\ ${ }^{9}$ Department of Pathology, Fujian Cancer Hospital, Fujian Medical University Cancer Hospital, Fuzhou, China \\ Contributions: (I) Conception and design: L Lei, WX Wang; (II) Administrative support: MY Fang, CW Xu; (III) Provision of study materials or \\ patients: YC Zhu, XX Pu, Y Fang, W Zhuang, YB Zhang, LP Wang; (IV) Collection and assembly of data: L Lei, WX Wang; (V) Data analysis and \\ interpretation: MY Fang, CW Xu; (VI) Manuscript writing: All authors; (VII) Final approval of manuscript: All authors. \\ \#These authors contributed equally to this work. \\ Correspondence to: Chun-Wei Xu, MD, PhD. Department of Pathology, Fujian Cancer Hospital, Fujian Medical University Cancer Hospital, No. 420, \\ Fuma Road, Fuzhou, China. Email: xuchunweibbb@163.com; Mei-Yu Fang, MD, PhD. Department of Chemotherapy, Zhejiang Cancer Hospital, \\ No. 1 Banshan East Street, Gongshu District, Hangzhou, China. Email: fangjade2004@icloud.com.
}

Background: $B R A F$ mutation plays a rare but aggressive oncogenic role in non-small cell lung cancer (NSCLC) patients. The controversy of first-line chemotherapy in patients with different $B R A F$ mutations exists. Here, we identified 41 stage IIIB/IV NSCLC patients with BRAF mutation from 3,669 NSCLC patients by next-generation sequencing (NGS) testing of ctDNA in plasma or tumor tissues.

Methods: Kaplan-Meier survival curves were used to compare the prognostic difference of progressionfree survival (PFS) and overall survival (OS) in different classes of $B R A F$ mutations. Multivariate Cox proportional-hazards regression was used to determine the hazard ratio (HR) of different prognostic factors in survival.

Results: A total of 40 stage IIIB/IV NSCLC patients with $B R A F$ mutation were further divided into four groups according to the updated functional classification of $B R A F$ mutations, $56.1 \%(23 / 41)$ of class $1,12.2 \%$ (5/41) of class 2, 12.2\% (5/41) of class 3 and 19.5\% (8/41) of others. The median PFS of patients after firstline pemetrexed-based chemotherapy was longer than other regimens of chemotherapy (7.0 vs. 4.0 months, $\mathrm{P}<0.001)$. The patients with class $1 B R A F$ mutation treated with pemetrexed-based first-line chemotherapy had a better OS than other regimens of chemotherapy (30 vs. 22 months, $\mathrm{P}<0.001)$. A significant improvement of OS was observed in patients with class 1 BRAF mutation than other groups (25 vs. 12,15 and 14 months, $\mathrm{P}<0.0001)$. Multivariate analysis showed that first-line pemetrexed-based chemotherapy was associated with better PFS and $\mathrm{OS}$ ( $\mathrm{HR}=0.16$ and 0.31 , respectively; $\mathrm{P}<0.001$ and 0.02 , respectively), as well as improved OS in patients with class $1 B R A F$ mutation than other classes ( $\mathrm{HR}=2.15, \mathrm{P}<0.001)$.

Conclusions: Pemetrexed-based regimen could be considered as first-line chemotherapy in advanced NSCLC patients with $B R A F$ mutants when target therapy is unavailable, especially in patients harboring class 1 mutations compared with other classes. 
Keywords: BRAF mutation; pemetrexed; non-small cell lung cancer (NSCLC); chemotherapy

Submitted Jan 10, 2020. Accepted for publication Jul 27, 2020.

doi: $10.21037 /$ tcr-20-480

View this article at: http://dx.doi.org/10.21037/tcr-20-480

\section{Introduction}

Lung cancer has always been the leading cause of cancer death in all populations worldwide (1). Conventional chemotherapies used to be the cornerstone for treatment in advanced non-small cell lung cancer (NSCLC) cancer patients (2). During the past three decades, the discovery of driver genes and target therapies have significantly improved the outcome in oncogenic-addictive NSCLC patients $(3,4)$. BRAF was proto-oncogene encoding a serine/ threonine-protein kinase which promotes cell proliferation and survival (5). BRAF mutations are commonly seen in melanoma (6) and papillary thyroid carcinoma (7) and also played as one of the major oncogenic drivers occurring in $2-4 \%$ NSCLC patients $(5,8)$. BRAF mutations are mainly localized in the kinase domain and about $50-80 \%$ of them are V600E mutation $(9,10)$. However, the prognostic value of V600E mutation remains unclear $(9,11)$ and nonV600E mutated cases showed distinctive and complicated characteristics from V600E mutant carriers (9).

Based on the increasing knowledge of the biological activation mechanism and response of inhibitors in NSCLC patients with $B R A F$ mutations, a functional mutation classification system has been established recently $(12,13)$. In detail, class 1 mutants refer to the $R A S$-independent kinase-activating V600 monomers; class 2 mutants refer to the $R A S$-independent kinase-activating dimers which are resistant to vemurafenib; class 3 refer to the $R A S$-dependent kinase-inactivating heterodimers. Previous data showed that the advanced NSCLC patients with $B R A F$ mutation (18 cases with V600E and 18 cases with non-V600E) had similar OS compared with patients without BRAF mutation, however, V600E-mutated patients tended to have shorter PFS after platinum-based chemotherapy compared with non-V600E-mutated patients (4.1 vs. 8.9 months; $\mathrm{P}=0.297$ ) (14). Increasing data support the recommendation of $B R A F$ and downstream pathway targeted therapy in advanced NSCLC patients with V600E mutation (15). However, the prognosis and treatment recommendation for patients with non-BRAF V600 mutations remains controversial $(16,17)$. BRAF inhibitor in the combination of downstream targets such as MEK inhibitor may be better than monotherapy by reducing the drug-resistance in patients with non-BRAF V600 mutations (18).

Although target therapy should be the promising firstline treatment for patients with $B R A F$ mutations, most of them still have to accept chemotherapy in conditions of inaccessible to target agents or progression from target therapy (19). Besides, the advance of molecular testing method could help us to explore more non-V600E mutations which would potentially contribute to the biological development of disease (20). Recently, results from one large cohort study from France showed that no clear evidence supports the influence of $B R A F$ status in outcomes of patients treated with chemotherapy and patients treated by the first-line taxane had the poorest PFS (19). In this study, we aimed to explore the clinical value of the functional classification of $B R A F$ mutations and optimizing the selection of chemotherapy in this cohort study. We present the following article in accordance with the STROBE reporting checklist (available at http://dx.doi. org/10.21037/tcr-20-480).

\section{Methods}

\section{Patients}

We conducted a multicenter, retrospective study involving several hospitals in China between May 2014 and May 2019. The genetic alterations results obtained from 3,669 plasma or tissue samples of NSCLC patients who underwent the next-generation sequencing (NGS) detection, and IIIB-IV with BRAF mutations were 41 cases. Histology subtyping was determined according to the 2015 World Health Organization classification. Tumor stage was based on the $7^{\text {th }}$ edition of the Lung Cancer Staging system from the American Joint Committee on Cancer. Age, smoking status, East Cooperative Oncology Group performance status, histology, disease stage, brain or bone metastasis, and molecular information were documented at first diagnosis. All clinical information, including diagnosis, treatment, and clinical outcome, was collected through the system and confirmed by local professional oncologists. Patients were followed from the date of diagnosis until the 
date of death from all causes or last approachable follow-up. Tumor response was evaluated according to the Response Evaluation Criteria in Solid Tumors (RECIST v1.1) (21). The treatment response was evaluated by CT scans at the baseline of initial therapy and every 6 weeks thereafter. The study was conducted in accordance with the Declaration of Helsinki (as revised in 2013). This study was approved by the Chinese Academy of Sciences University Cancer Hospital (Zhejiang Cancer Hospital) Ethics Committee (No.: IRB-2020-188) and written informed consent was obtained from each patient to use the clinical data for research before the medical intervention started.

\section{Molecular detection}

Targeted region capture combined NGS was performed for the 41 NSCLC patients. Genomic DNA sequencing libraries were prepared using the protocols recommended by the TruSeq DNA Library Preparation Kit (Illumina, San Diego, CA, USA). For samples close to the minimum input requirement, additional pre-capture polymerase chain reaction cycles were performed to generate sufficient product for hybridization. The libraries were hybridized to custom-designed probes (Integrated DNA Technology, Coralville, IA, USA) including all exons of 170 genes and selected introns of anaplastic lymphoma kinase, RET, and ROS1 for the detection of genomic rearrangements. DNA sequencing was performed on a HiSeq3000 sequencing system (Illumina) with $2 \times 75$ bp paired-end reads. The reads were aligned to the human genome build GRCh37 using BWA (a Burrows-Wheeler aligner). Somatic single nucleotide variant and indel calls were generated using MuTect and GATK, respectively. Somatic copy number alterations were identified with CONTRA. Genomic rearrangements were identified by software developed inhouse to analyze chimeric read pairs.

\section{Statistical analyses}

Kaplan-Meier curves and the two-sided log-rank test were used for univariate survival analyses. The Cox proportional hazards model was used to complete the uniand multivariate survival analyses with the hazard ratio (HR) and corresponding 95\% confidence interval. Progressionfree survival (PFS) was defined as the time from the date of initial treatment to the date of systemic progression or death or censored at the date of last follow up, whichever came first to trigger the event. Significance between groups was defined as $\mathrm{P}$ values $<0.05$. Statistical analyses were performed using the R software/environment (URL http:// www.R-project.org).

\section{Results}

\section{Clinicopathologic characteristics}

We identified 66 NSCLC patients with $B R A F$ mutation from 3,669 NSCLC patients, and 41 patients with advanced NSCLC with $B R A F$ mutation were enrolled in this study (Figure 1). There were 36 males and 5 females, with a median age of 69 years (range, 34-83 years). The smoking history was divided into former or current $(n=4)$ and never $(\mathrm{n}=37)$.

\section{BRAF mutations}

Forty-one patients with IIIB/IV stages of NSCLC had $B R A F$ mutations. The $B R A F$ mutants in this study were classified into four groups according to reference (22), included class 1 [n=23(56.1\%)], class $2[\mathrm{n}=5(12.2 \%)]$, class $3[\mathrm{n}=5(12.2 \%)]$, and others $[\mathrm{n}=8(19.5 \%)]$ (Table 1, Figure 2). Eight patients were stage IIIB and 33 were stage IV according to the IASLC classification of lung adenocarcinoma. The detailed characteristics are listed in Table 2. Collectively, the frequency of BRAF mutants included $97.6 \%(40 / 41)$ point mutations and $2.4 \%(1 / 41)$ missense mutation. The concurrent oncogenic alterations included EGFR (n=3), KRAS (n=1), EML-ALK (n=1) (Figure 2). The baseline clinic-genetic characteristics and chemotherapy in all patients and comparison among the four groups of patients were shown in Tables 2 and 3, respectively. No significant difference existed concerning age, gender, ECOG PS, clinical stage at diagnosis, smoking status, brain and bone metastasis, concurrent oncogenic mutations, and first- and second-lines of pemetrexed-based chemotherapy among four groups (Table 3).

\section{First-line chemotherapy}

All patients received a first-line chemotherapy regimen, including pemetrexed/platinum $(n=13)$, pemetrexed monotherapy $(\mathrm{n}=2)$, paclitaxel/platinum $(n=3)$ and gemcitabine/platinum $(n=19)$, others $(n=4)$. All chemotherapy regimens were calculated according to the standard dose of the NCCN guideline [pemetrexed $\left(500 \mathrm{mg} / \mathrm{m}^{2}\right.$ on day 1$)$; gemcitabine 


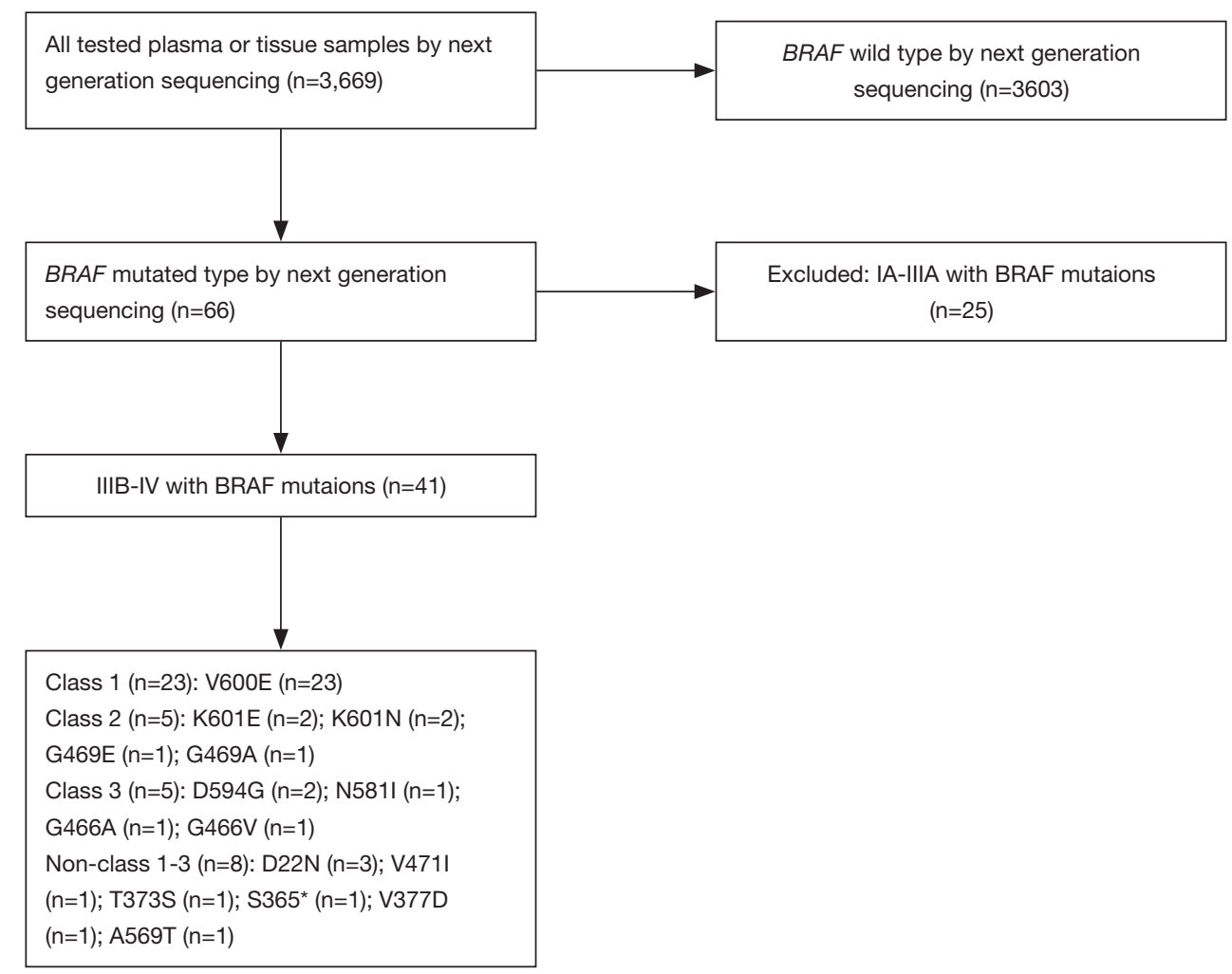

Figure 1 Flow chart of this cohort study. * represent Amino acid loss.

Table $1 B R A F$ mutations included in each functional class

\begin{tabular}{ll}
\hline Class & BRAF mutations \\
\hline Class 1 & V600E/L/D/K/M/R \\
Class 2 & P367L/S, E451Q, G464V/E/A, G469A/V/R/S, L485W, N486_A489delinK, N486_P490del, E586K, L597Q/R/S/N, \\
& T599T/S/I/K, K601E/N/T, K601_S602delinsNT, A712T, KDD, fusions \\
Class 3 & D287H, V459L, G466V/E/A, S467L, G469E, N581S/I/T, D594A/G/H/N, F595L, G596D/R \\
\hline
\end{tabular}

(1,000-1,250 $\mathrm{mg} / \mathrm{m}^{2}$ on days 1 and 8); paclitaxel $\left(175 \mathrm{mg} / \mathrm{m}^{2}\right.$ on day 1 ); carboplatin (AUC $=5$ on day 1 ); and cisplatin $\left(75 \mathrm{mg} / \mathrm{m}^{2}\right.$ on day 1$)$ ]. Of the 41 patients, 2 received chemotherapy in combination with bevacizumab and 3 received icotinib after first-line chemotherapy. The ORR and DCR of pemetrexed-based chemotherapy were $33.3 \%(5 / 15)$ and $53.3 \%(8 / 15)$, respectively. The ORR and DCR of the other chemotherapy regimens were $26.9 \%$ (7/26) and 42.3\% (11/26), respectively. The median PFS (mPFS) for the 15 patients who received pemetrexedbased chemotherapy was 7.0 months, while the mPFS of the 26 patients who received other chemotherapy regimens was 4.0 months $[\mathrm{P}<0.001, \mathrm{HR}=0.31$ (95\% CI, 0.15-0.61);
Table 4, Figure 3A]. Of 23 patients with class $1 B R A F$ mutations, the pemetrexed-based chemotherapy-treated patients $(n=10)$ have better mOS than non-pemetrexedbased chemotherapy-treated patients $(n=13)$ was significantly different [30.0 vs. 22.0 months, $\mathrm{P}<0.001$, HR $=0.29$ (95\% CI, 0.12-0.73); Figure 3B]. Overall survival of patients with class $1 B R A F$ mutation treated with pemetrexed-based or other chemotherapy regimens as first-line chemotherapy (30 vs. 22 months, $\mathrm{P}=0.0002$ ) (Figure 3C).

\section{Overall survival (OS)}

The median OS (mOS) of the 41 patients IIIB/IV NSCLC 
A

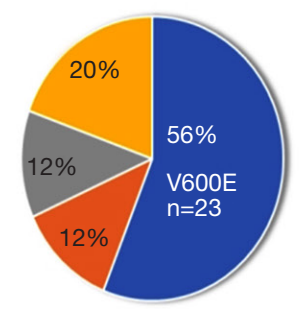

B

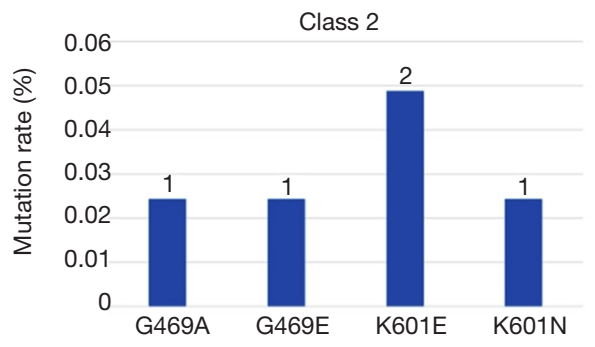

C

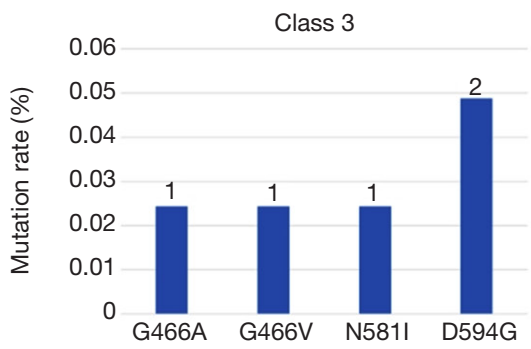

D

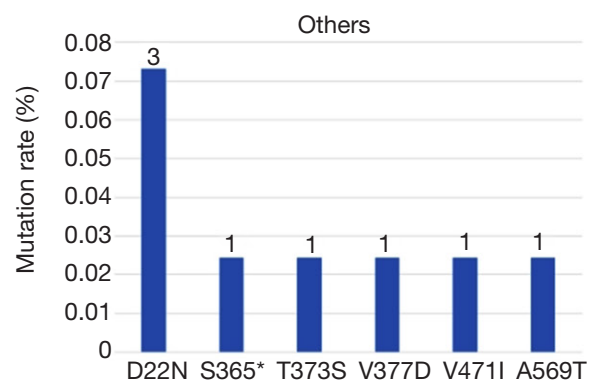

$E$

Altered in 41 (100\%) of 41 samples.



Figure 2 Distribution of V-RAF murine sarcoma viral oncogene homolog B $(B R A F)$ mutants in 41 advanced non-small cell lung Cancer (NSCLC) patients according to different classes by functional classification [(A) mutation proportion of each subtype, (B) number of Class 2, (C) number of Class 3, (D) number of others]. Heatmap showed the next-generation sequencing results for mutation spectrum of $B R A F$ mutants in all patients $(\mathrm{E}) .{ }^{*}$ represent Amino acid loss. 
Table 2 Clinical characteristics of the study population $(n=41)$

\begin{tabular}{|c|c|}
\hline Characteristic & Number (\%) \\
\hline \multicolumn{2}{|l|}{ Gender } \\
\hline Male & $36(87.8)$ \\
\hline Female & $5(12.2)$ \\
\hline \multicolumn{2}{|l|}{ Age (years) } \\
\hline Mean & 66.1 \\
\hline$\leq 60$ & $7(17.1)$ \\
\hline$>60$ & $34(82.9)$ \\
\hline \multicolumn{2}{|l|}{ Smoking status } \\
\hline No & $37(90.2)$ \\
\hline Yes & $4(9.8)$ \\
\hline \multicolumn{2}{|l|}{ Histology } \\
\hline Adenocarcinoma & $29(70.7)$ \\
\hline Non-adenocarcinoma & $12(29.3)$ \\
\hline \multicolumn{2}{|l|}{ ECOG PS } \\
\hline $0-1$ & $33(80.5)$ \\
\hline$\geq 2$ & $8(19.5)$ \\
\hline \multicolumn{2}{|l|}{ Clinical stage } \\
\hline IIIB & $8(19.5)$ \\
\hline IV & $33(80.5)$ \\
\hline \multicolumn{2}{|c|}{ Brain metastases before treatment } \\
\hline No & $38(92.7)$ \\
\hline Yes & $3(7.3)$ \\
\hline \multicolumn{2}{|c|}{ Bone metastases before treatment } \\
\hline No & $34(82.9)$ \\
\hline Yes & $7(17.1)$ \\
\hline \multicolumn{2}{|l|}{ BRAF-mutant group } \\
\hline Class 1 & $23(56.1)$ \\
\hline Class 2 & $5(12.2)$ \\
\hline Class 3 & $5(12.2)$ \\
\hline Others & $8(19.5)$ \\
\hline \multicolumn{2}{|c|}{ Concurrent oncogenic mutations } \\
\hline No & $36(87.8)$ \\
\hline Yes & $5(12.2)$ \\
\hline \multicolumn{2}{|l|}{ First-line chemotherapy } \\
\hline Pemetrexed-based & $15(36.6)$ \\
\hline Non-pemetrexed & $26(63.4)$ \\
\hline \multicolumn{2}{|l|}{ Second-line chemotherapy } \\
\hline Pemetrexed-based & $3(7.3)$ \\
\hline Non-pemetrexed based & $38(92.7)$ \\
\hline
\end{tabular}

patients was 22.0 months (Figure $4 A$ ). A significant improvement of OS existed in patients with $B R A F$ mutation of class 1 compared with class 2 , class 3 and others $(\mathrm{n}=23.0,5.0,5.0,8.0 ; 25.0$ vs. $12.0,15.0$ and 14.0 months, $\mathrm{P}<0.0001$; Figure $4 B)$. Multivariate analysis revealed that the pemetrexed-based chemotherapy and class $1 B R A F$ mutated were independent prognostic factors for OS in all patients after adjusting for known characteristic factors $(\mathrm{P}<0.001$; Table 4).

\section{Discussion}

We have carried out the study to explore the efficacy of pemetrexed-based chemotherapy in advanced NSCLC patients with the different functional classification of $B R A F$ mutations. Patients who treated by first-line pemetrexedbased chemotherapy had better PFS and OS than other regimens. Furthermore, patients with class $1 B R A F$ mutants had a better OS than other groups after first-line pemetrexed-based chemotherapy. As far as we know, this is the first study reported the positive association between the efficacy of pemetrexed-based chemotherapy and the functional classification of $B R A F$ mutation in advanced NSCLC patients.

$B R A F$ mutations in NSCLC have been well-known as the unique driver-gene alterations than common mutations (23). Dagogo-Jack et al. (24) reported a significantly longer OS for $B R A F$-mutant NSCLC patients with class 1 than other classes after first-line chemotherapy (1 vs. 2, $\mathrm{P}<0.001 ; 1$ vs. 2, $\mathrm{P}=0.023$ ). However, Lin et al. (22) found comparable OS outcomes among all classes of $B R A F$ mutation by 28.6, 13.9 and 20.2 months for classes 1,2 and 3 , respectively $(\mathrm{P}=0.585)$. The controversy of those results may intratumor heterogeneity of $B R A F$ mutations and response to different regimens of chemotherapy. Nevertheless, according to the available evidence, patients with class 2 and 3 appeared to have a worse outcome than patients with class 1 .

Before the $B R A F$ mutation story initiated from melanoma to the unique subset in NSCLC (25), conventional platinum-based chemotherapy is the cornerstone treatment in advanced NSCLC patients with $B R A F$ mutations (26). Platinum-based chemotherapies were not effective in metastatic NSCLC patients with $B R A F$ V600E (14). Therefore, searching for better chemotherapeutic agents become very important when target therapy is inaccessible. Pemetrexed is a multitargeted antifolate and it could be used in combination with platinum 
Table 3 Comparison of clinical characteristics of BRAF-mutant groups $(n=41)$

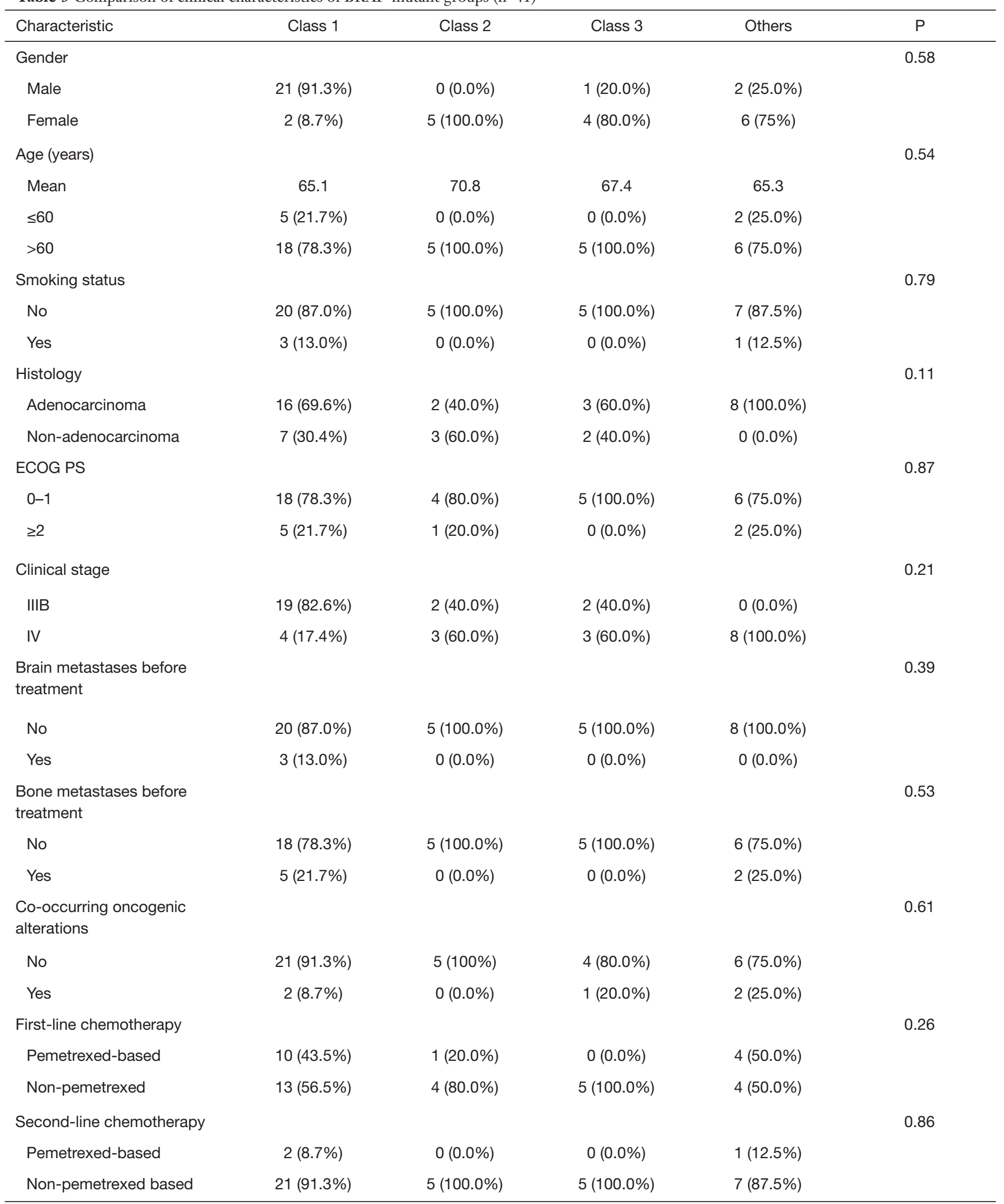


Table 4 Results of multivariate Cox regression model in BRAF mutation patients

\begin{tabular}{|c|c|c|c|c|c|c|}
\hline Covariant & Coefficient & Standard error & $P$ value & $\mathrm{HR}$ & \multicolumn{2}{|c|}{$95 \% \mathrm{Cl}$} \\
\hline Age $(\leq 60$ vs. $>60)$ & 0.99 & 0.57 & 0.99 & 1.01 & $3.27 \times 10^{-1}$ & 3.00 \\
\hline Gender (female vs. male) & 0.31 & 0.88 & 0.18 & 0.31 & $5.46 \times 10^{-2}$ & 1.71 \\
\hline Smoking status (no vs. yes) & 0.62 & 0.62 & 0.45 & 1.6 & $1.87 \times 10^{-1}$ & 2.09 \\
\hline Clinical stage (IIIB vs. IV) & 0.73 & 0.51 & 0.54 & 1.37 & $2.67 \times 10^{-1}$ & 2.00 \\
\hline $\begin{array}{l}\text { First-line chemotherapy } \\
\text { (pemetrexed-based vs. } \\
\text { non-pemetrexed) }\end{array}$ & 49.22 & 1.39 & 0.005 & 0.02 & 3.23 & 750.62 \\
\hline $\begin{array}{l}\text { Co-occurring oncogenic } \\
\text { alterations (no vs. yes) }\end{array}$ & 1.88 & 0.86 & 0.46 & 0.53 & $9.87 \times 10^{-2}$ & 2.87 \\
\hline
\end{tabular}

$\mathrm{HR}$, hazard ratio; $\mathrm{Cl}$, confidence interval.

A

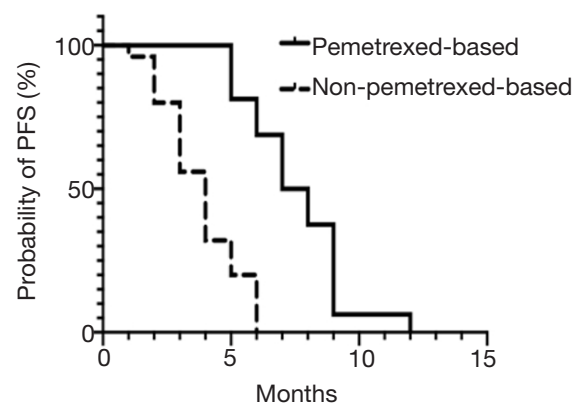

B

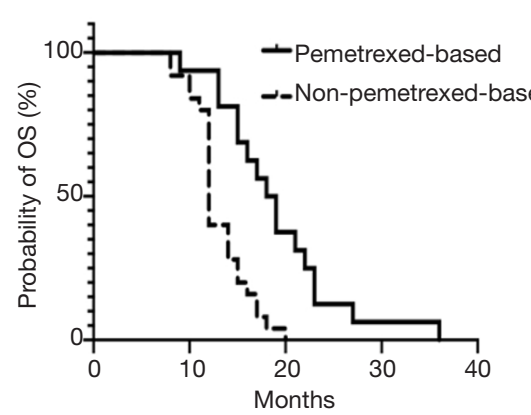

C

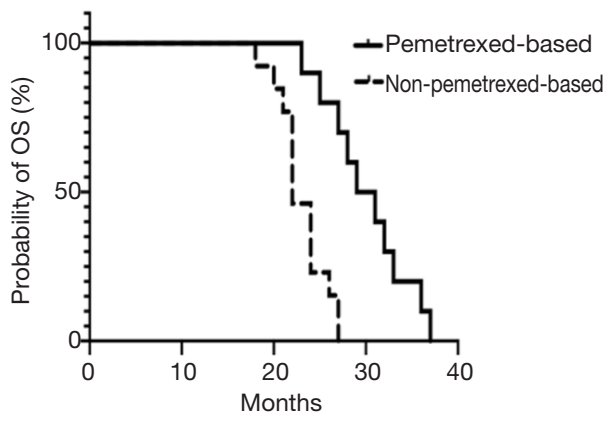

Figure 3 Survival analysis. (A) Progression-free survival of all patients with $B R A F$ mutation treated with first-line pemetrexedbased or other chemotherapy (7.0 vs. 4.0 months, $\mathrm{P}<0.001)$; (B) overall survival of patients with class $1 B R A F$ mutation treated with pemetrexed-based or other chemotherapy regimens as first-line chemotherapy (30.0 vs. 22.0 months, $\mathrm{P}<0.001$ ); (C) overall survival of patients with class $1 \mathrm{BRAF}$ mutation treated with pemetrexed-based or other chemotherapy regimens as first-line chemotherapy (30 vs. 22 months, $\mathrm{P}=0.0002)$.

in first-line or monotherapy for subsequent lines and as well as maintenance therapy (27). Over eight years survival benefit from pemetrexed treatment in an advanced NSCLC case with $B R A F$ mutation has been reported in Japan recently (28). The higher frequency of adenocarcinoma $(69.6 \%)$ in patients with class $1 B R A F$ mutation could also indicate the potential better response to pemetrexed based chemotherapy (29). Liang and colleagues have launched interesting research on long-term pemetrexed response in NSCLC with driver oncogenes (30). Although BRAF mutation has not included in their research, the mechanism of significantly better survival from long-term pemetrexed 
A

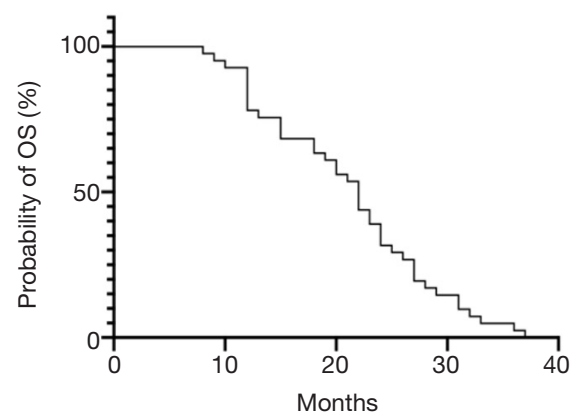

B

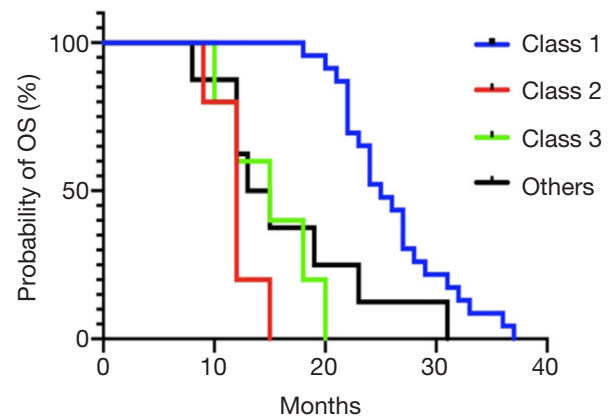

Figure 4 Survival analysis. (A) The median overall survival (OS) of the 41 patients was 22.0 months; (B) a significant improvement of OS was seen in lung cancer patients with class 1 BRAF mutation than patients with other classifications (25.0 vs. $12.0,15.0$ and 14.0 months, $\mathrm{P}<0.0001)$.

response in oncogenic-addiction patients should be explored.

We have also explored the concurrent driver genetic alterations in this study. The advanced NSCLC patients with $B R A F$ mutation have seldomly co-occurrence with other driver genes (5). Under screening by the known driver-gene panel in NSCLC, only 5 patients have been detected and three of them harboring EGFR mutation have received icotinib. The other two patients with KRAS A146T and EML4-ALK respectively did not receive any target therapies. Of note, two patients with class $1 B R A F$ mutation co-occurring with EGFR mutation but not KRAS consistent with mutual exclusivity existed between class 1 $B R A F$ mutation and KRAS mutation in a previous study (22).

There are some limitations to our research. Firstly, this is a retrospective study and the enrollment of patients could be biased. However, it is not easy for us to collected patients with a rare mutation from a large cohort by NGS testing. Secondly, although the standard recommendation for patients with $B R A F$ V600E mutation should be the combination of BRAF and MEK inhibitors (31), none of the patients have ever been treated by targeted therapy due to numeric reasons. We believe that the value of our research is to pursue the most available and effective chemotherapy for those patients who could not afford those expensive targeted drugs outside of clinical trials.

\section{Conclusions}

Pemetrexed-based chemotherapy treatments were more effective than other regimens in advanced NSCLC patients with $B R A F$ mutations. The best clinical benefit of first-line pemetrexed-based chemotherapy was observed in patients with class $1 B R A F$ mutants among all patients. In that case, we assumed that pemetrexed-based chemotherapy could be an alternative treatment of choice in NSCLC patients with $B R A F$ mutation when the targeted therapy is unavailable. Besides, more research and workforce are warranted in this area.

\section{Acknowledgments}

Funding: the Medical Scientific Research Foundation of Zhejiang Province of China (2019RC027), Zhejiang Public Welfare Technology Research Program (LGJ20H160001, LQ19H160004), Science and Technology Planning Project of Zhejiang Province (LGF19H160002), Zhejiang Administration of Traditional Chinese Medicine Foundation (2013ZQ005), Zhejiang Traditional Chinese Medicine Science Fund Project (2020ZB037), Scientific Research Foundation of Zhejiang Medical Association (2019ZYC-A76) and Xisike-Hanson Cancer Research Foundation (Y-HS2019-20).

\section{Footnote}

Reporting Checklist: The authors have completed the STROBE reporting checklist. Available at http://dx.doi. org/10.21037/tcr-20-480

Data Sharing Statement: Available at http://dx.doi. org/10.21037/tcr-20-480

Peer Review File: Available at http://dx.doi.org/10.21037/tcr- 
$20-480$

Conflicts of Interest: All authors have completed the ICMJE uniform disclosure form (available at http://dx.doi. org/10.21037/tcr-20-480). The authors have no conflicts of interest to declare.

Ethical Statement: The authors are accountable for all aspects of the work in ensuring that questions related to the accuracy or integrity of any part of the work are appropriately investigated and resolved. The study was conducted in accordance with the Declaration of Helsinki (as revised in 2013). The study was approved by the Chinese Academy of Sciences University Cancer Hospital (Zhejiang Cancer Hospital) Ethics Committee (No.: IRB-2020-188) and written informed consent was taken from all the patients.

Open Access Statement: This is an Open Access article distributed in accordance with the Creative Commons Attribution-NonCommercial-NoDerivs 4.0 International License (CC BY-NC-ND 4.0), which permits the noncommercial replication and distribution of the article with the strict proviso that no changes or edits are made and the original work is properly cited (including links to both the formal publication through the relevant DOI and the license). See: https://creativecommons.org/licenses/by-nc-nd/4.0/.

\section{References}

1. Dela Cruz CS, Tanoue LT, Matthay RA. Lung cancer: epidemiology, etiology, and prevention. Clin Chest Med 2011;32:605-44.

2. Lwin Z, Riess JW, Gandara D. The continuing role of chemotherapy for advanced non-small cell lung cancer in the targeted therapy era. Journal of thoracic disease 2013;5 Suppl 5:S556-S564.

3. Lynch TJ, Bell DW, Sordella R, et al. Activating mutations in the epidermal growth factor receptor underlying responsiveness of non-small-cell lung cancer to gefitinib. N Engl J Med 2004;350:2129-39.

4. Solomon BJ, Mok T, Kim DW, et al. First-Line Crizotinib versus Chemotherapy in ALK-Positive Lung Cancer. N Engl J Med 2014;371:2167-77.

5. Luk PP, Yu B, Ng CC, et al. BRAF mutations in non-small cell lung cancer. Transl Lung Cancer Res 2015;4:142-8.

6. Edlundh-Rose E, Egyha S, Omholt K, et al. NRAS and BRAF mutations in melanoma tumours in relation to clinical characteristics: a study based on mutation screening by pyrosequencing. Melanoma Res 2006;16:471-8.

7. Cohen Y, Xing M, Mambo E, et al. BRAF mutation in papillary thyroid carcinoma. J Natl Cancer Inst 2003;95:625-7.

8. Baik CS, Myall NJ, Wakelee HA. Targeting BRAFMutant Non-Small Cell Lung Cancer: From Molecular Profiling to Rationally Designed Therapy. Oncologist 2017;22:786-96.

9. Tissot C, Couraud S, Tanguy R, et al. Clinical characteristics and outcome of patients with lung cancer harboring BRAF mutations. Lung Cancer 2016;91:23-8.

10. Bracht JWP, Karachaliou N, Bivona T, et al. BRAF Mutations Classes I, II, and III in NSCLC Patients Included in the SLLIP Trial: The Need for a New Pre-Clinical Treatment Rationale. Cancers (Basel) 2019;11:1381.

11. Kinno T, Tsuta K, Shiraishi K, et al. Clinicopathological features of nonsmall cell lung carcinomas with BRAF mutations. Ann Oncol 2014;25:138-42.

12. Wan PT, Garnett MJ, Roe SM, et al. Mechanism of activation of the RAF-ERK signaling pathway by oncogenic mutations of BRAF. Cell 2004;116:855-67.

13. Yao Z, Yaeger R, Rodrik-Outmezguine VS, et al. Tumours with class 3 BRAF mutants are sensitive to the inhibition of activated RAS. Nature 2017;548:234.

14. Cardarella S, Ogino A, Nishino M, et al. Clinical, pathologic, and biologic features associated with BRAF mutations in non-small cell lung cancer. Clin Cancer Res 2013;19:4532-40.

15. Planchard D, Smit EF, Groen HJM, et al. Dabrafenib plus trametinib in patients with previously untreated BRAFV600E-mutant metastatic non-small-cell lung cancer: an open-label, phase 2 trial. Lancet Oncol 2017;18:1307-16.

16. Noeparast A, Teugels E, Giron P, et al. Non-V600 BRAF mutations recurrently found in lung cancer predict sensitivity to the combination of Trametinib and Dabrafenib. Oncotarget 2016;8:60094-108.

17. Gower A, Wang Y, Giaccone G. Oncogenic drivers, targeted therapies, and acquired resistance in non-smallcell lung cancer. J Mol Med 2014;92:697-707.

18. Oxnard GR, Binder A, Jänne PA. New targetable oncogenes in non-small-cell lung cancer. J Clin Oncol 2013;31:1097.

19. Couraud S, Barlesi F, Fontaine-Deraluelle C, et al. Clinical outcomes of non-small-cell lung cancer patients with BRAF mutations: results from the French Cooperative 
Thoracic Intergroup biomarkers France study. Eur J Cancer 2019;116:86-97.

20. Tuononen K, Mäki-Nevala S, Sarhadi VK, et al. Comparison of targeted next-generation sequencing (NGS) and real-time PCR in the detection of EGFR, KRAS, and BRAF mutations on formalin-fixed, paraffinembedded tumor material of non-small cell lung carcinoma-superiority of NGS. Genes Chromosomes Cancer 2013;52:503-11.

21. Eisenhauer EA, Therasse P, Bogaerts J, et al. New response evaluation criteria in solid tumours: revised RECIST guideline (version 1.1). Eur J Cancer 2009;45:228-47.

22. Lin Q, Zhang H, Ding H, et al. The association between BRAF mutation class and clinical features in BRAF-mutant Chinese non-small cell lung cancer patients. J Transl Med 2019;17:298

23. Brustugun OT, Khattak AM, Trømborg AK, et al. BRAFmutations in non-small cell lung cancer. Lung Cancer 2014;84:36-8.

24. Dagogo-Jack I, Martinez P, Yeap BY, et al. Impact of BRAF Mutation Class on Disease Characteristics and Clinical Outcomes in BRAF-mutant Lung Cancer. Clin Cancer Res 2019;25:158.

25. Brose MS, Volpe P, Feldman M, et al. BRAF and RAS mutations in human lung cancer and melanoma. Cancer Res 2002;62:6997-7000.

Cite this article as: Lei L, Wang WX, Zhu YC, Pu XX, Fang Y, Wang H, Zhuang W, Zhang YB, Wang LP, Xu CW, Fang MY. Association between $B R A F$ mutant classification and the efficacy of pemetrexed-based chemotherapy in Chinese advanced nonsmall cell lung cancer patients: a multicenter retrospective study. Transl Cancer Res 2020;9(10):6039-6049. doi: 10.21037/tcr$20-480$
26. Huang CL, Yokomise H, Fukushima M, et al. Tailor-made chemotherapy for non-small cell lung cancer patients. Future Oncol 2006;2:289-99.

27. Grønberg BH, Bremnes RM, Fløtten Ø, et al. Phase III study by the Norwegian lung cancer study group: pemetrexed plus carboplatin compared with gemcitabine plus carboplatin as first-line chemotherapy in advanced Non-small-cell lung cancer. J Clin Oncol 2009;27:3217-24.

28. Nakanishi Y, Nakagawa Y, Tsujino I, et al. Favorable outcome with pemetrexed treatment for advanced BRAFV600E-positive lung adenocarcinoma in a patient followed up over 8 years. J Thorac Oncol 2018;13:e199-e202.

29. Peterson P, Park K, Fossella F, et al. Is pemetrexed more effective in adenocarcinoma and large cell lung cancer than in squamous cell carcinoma? A retrospective analysis of a phase III trial of pemetrexed vs docetaxel in previously treated patients with advanced non-small cell lung cancer (NSCLC). J Thorac Oncol 2007;2:S851.

30. Liang Y, Wakelee HA, Neal JW. Relationship of Driver Oncogenes to Long-Term Pemetrexed Response in Non-Small-Cell Lung Cancer. Clin Lung Cancer 2015;16:366-73.

31. Hanna N, Johnson D, Temin S, et al. Systemic Therapy for Stage IV Non-Small-Cell Lung Cancer: American Society of Clinical Oncology Clinical Practice Guideline Update. J Clin Oncol 2017;35:3484-515. 